\title{
Is sporadic colorectal cancer more aggressive in young people and should the age of colonoscopy screening be reduced?
}

\author{
Surek $\mathrm{A}^{1}$, Ferahman $\mathrm{S}^{1}$, Gemici $\mathrm{E}^{1}$, Corba $\mathrm{K}^{1}$, Bozkurt $\mathrm{MA}^{1}$, Donmez $\mathrm{T}^{1}$, Karabulut $\mathrm{M}^{1}$, Alis $\mathrm{H}^{2}$ \\ Department of General Surgery, Ministry of Health Bakirkoy Dr Sadi Konuk Training and Research \\ Hospital, Istanbul, Turkey. ahmetsurek82@hotmail.com
}

\begin{abstract}
OBJECTIVES: The present study aims to report the incidence of colorectal cancer patients under 50 years of age and to compare its aggressiveness with colorectal cancer patients over 50 years of age.

BACKGROUND: Recently, the incidence of colorectal cancer at younger ages has increased, and colorectal cancers in young people have a more aggressive course due to late screening programs.

METHOD: The files of patients who were operated for colorectal cancer were reviewed retrospectively. Information on the patients such as gender, age, BMI, type and duration of symptoms, location of the tumor, TNM staging, pathology results, operative procedure, morbidity and mortality rates were recorded. Admission complaints, symptom onset time, tumor locations, pathological findings and tumor stages were compared between patients under and over the age of 50 .

RESULTS: The incidence of colorectal cancer under 50 was $21 \%(56 / 267)$. The age group of $40-49$ was found to be the most common age range under the age of 50 , with a colorectal cancer rate of $68 \%$. In patients under the age of 50 , higher invasion of the tumor to the serosa, low differentiation of the tumor in terms of histological findings in a higher number of patients and higher mucin component of the tumors and higher N2 lymph node involvement ratio and the tumor was located more in the lower rectum were statistically significant when compared to patients over the age of $50(p=0.026, p=0.018, p=0.002, p=0.042$, $p=0.006$; respectively).

CONCLUSION: The incidence of colorectal cancer has increased at younger ages and has a more aggressive course. Screening programs should be modified (Tab. 4, Fig. 2, Ref. 45). Text in PDF www.elis.sk KEY WORDS: colorectal cancer, colonoscopy screening, young people.
\end{abstract}

\section{Introduction}

Colorectal cancer (CRC) is the 3rd most common malignant neoplasm in the world. Every year, 1-2 million people get colorectal cancer and around 600,000 people die because of it (1, 2 ). The incidence of the disease is low under 50 years of age but increases strongly with advanced age. Cases are seen in over 55 years of age, around $90 \%$. The median diagnosis age in developed countries has been reported as approximately 70 . The proportion of cases diagnosed in individuals under the age of 50 in the USA increased from $6 \%$ in 1990 to $11 \%$ in 2013 as a result of the increase in incidence rates of CRC in younger age groups (3-6). This trend shows that young CRC patients need more attention. It is assumed that $\mathrm{CRC}$ has different biological behavior in young patients than in older patients, more patients are at an advanced stage when diagnosed and have more aggressive histological fea-

\footnotetext{
${ }^{1}$ Department of General Surgery, Ministry of Health Bakirkoy Dr Sadi Konuk Training and Research Hospital, Istanbul, Turkey, and ${ }^{2}$ Department of General Surgery, Istanbul Aydin Univercity,Istanbul, Turkey

Address for correspondence: A. Surek, Bakirkoy Dr. Sadi Konuk Egitim ve Arastirma Hastanesi, Genel Cerrahi 4. Kat Zuhuratbaba Mah. Tevfik Saglam Cd. No:11 Bakirkoy, Istanbul, Turkey.

Phone: +905326384098
}

tures (7). In some population-based studies, it has been stated that young colorectal cancers have a better course $(8,9)$.

Colonoscopy is used for CRC scanning in an increasing number of countries. When a colonoscopy scan is recommended as the primary screening test, it typically begins at the age of 50 or 55 (10-12). Based on the modeling results and the increasing incidence of CRC in the young population, it has been proposed to start screening at the age of 45 in average-risk populations in the recently published American Cancer Association guidelines (13).

The present study aims to report the incidence of colorectal cancer patients under 50 years of age who have been operated in a single center in the last 3 years due to the increase in the incidence of colorectal cancer in recent years and to compare them with patients with colorectal cancer over 50 years of age in terms of locations of tumor, pathology results, and stages.

\section{Material and methods}

The files of patients who were operated in elective condition for colorectal cancer in the general surgery clinic between January 2017 and January 2020 were reviewed retrospectively. Patients older than 18 years, who had alarm symptoms during the outpatient clinic admission and who did not have a family history of cancer or a cancer-prone syndrome were included in the 


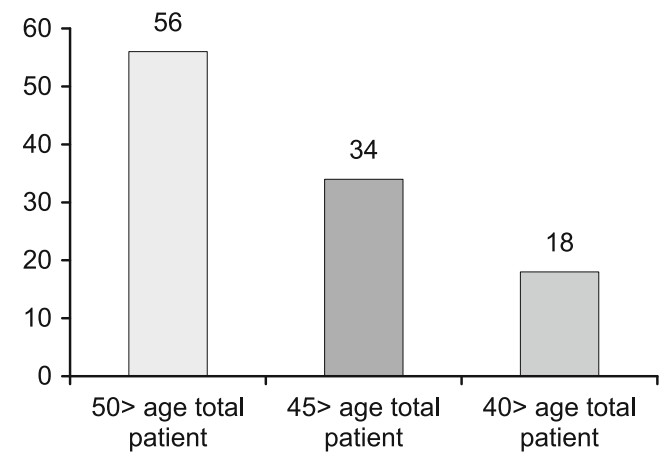

Fig. 1. Number of patient according to age.

study. Patients under the age of 18 and who had a family history of cancer or a syndrome that could predispose to cancer were excluded from the study.

Information on the patients such as gender, age, BMI, type and duration of symptoms, location of the tumor, stage of the disease in diagnosis (TNM staging), pathology results, histological classification, operative procedure, morbidity and mortality rates were recorded.

Admission complaints, symptom onset time, tumor locations, pathological findings, histological features of tumor and tumor stages were compared between patients under and over the age of 50 .

\section{Statistical analysis}

The Statistical Package for the Social Sciences 24.0 program was used for the statistical analysis of the variables. Independent Samples t-Test and descriptive statistical methods were used for binary group comparisons of normally distributed parameters. The Pearson Chi-Square test was used in the analysis of qualitative data. The significance was evaluated at $\mathrm{p}<0.01$ and $\mathrm{p}<0.05$ levels.

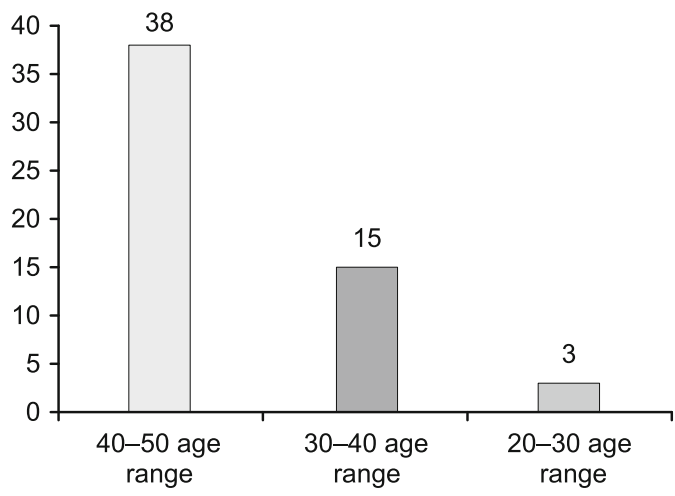

Fig. 2. Number of patient according to age range.

\section{Results}

Between January 2017 and January 2020, 273 patients were operated in our clinic for colorectal cancer. A total of 6 patients were excluded from the study because 2 patients had familial polyposis syndrome, 3 patients had a family history of colorectal cancer and 1 patient developed colorectal cancer on the background of ulcerative colitis. Only one of the 6 patients excluded from the study was under the age of 50 .

When the files of 267 patients included in the study were examined, it was seen that 56 colorectal cancer patients who did not have any family history and disease that could cause familial genetic predisposition were under 50 years and 211 patients were over 50 years of age. In the present study, the incidence of colorectal cancer under 50 was $21 \%(56 / 267)$. The incidence below the age of 45 was $14.23 \%(38 / 267)$ and the incidence below the age of 40 was $6.74 \%$ (18/267) (Fig. 1). The age range of the patients was between $22-49$. The average age was 42.2 , while $3(1.12 \%)$ patients were in the $20-30,15(5.63 \%)$ patients were in the $30-40$, and $38(14.23 \%)$ patients were in the $40-50$ age range (Fig. 2). In terms of gender distribution, it was seen that $20(35 \%)$ patients were female and 36 (65\%) patients were male. The mean BMI of the patients was 27.3 (22-34).

Rectal bleeding was the most common symptom seen in patients. Of the colorectal cancer patients aged $50>, 32(57.2 \%)$ had rectal bleeding, 18 (32.1\%) had changes in bowel habits (diarrhea and constipation), 12 $(21.4 \%)$ had abdominal pain, 6 (10.7\%) had weight loss and $4(7.1 \%)$ had vomiting. Compared to patients over 50 years of age, it was significant that rectal bleeding was higher in patients under 50 years of age, whereas more changes in bowel habits were significant in patients over 50 years of age $(\mathrm{p}=0.029, \mathrm{p}=0.032$; respectively) (Tab. 1$)$.

Considering the time between the onset of symptoms and the time of diagnosis, it was found that 6 patients applied 1 month af- 
Tab. 3. Surgical and histological findings and complications of patients under $\mathbf{5 0 .}$

\begin{tabular}{|c|c|}
\hline \multicolumn{2}{|l|}{ Surgeries performed } \\
\hline Laparoscopic low anterior resection & $14(25 \%)$ \\
\hline Open low anterior resection & $3(5.35 \%)$ \\
\hline Robotic low anterior resection & $1(1.78 \%)$ \\
\hline Laparoscopic anterior resection & $7(12.5 \%)$ \\
\hline Open anterior resection & $7(12.5 \%)$ \\
\hline Abdominoperineal resection & $2(3.57 \%)$ \\
\hline Laparoscopic left hemicolectomy & $3(5.35 \%)$ \\
\hline Open left hemicolectomy & $2(3.57 \%)$ \\
\hline Laparoscopic right hemicolectomy & $7(12.5 \%)$ \\
\hline Open right hemicolectomy & $3(5.35 \%)$ \\
\hline Low anterior resection + liver metastasectomy & $3(5.35 \%)$ \\
\hline Abdominoperineal resection + liver metastasectomy & $1(1.78 \%)$ \\
\hline Right hemicolectomy + liver metastasectomy & $1(1.78 \%)$ \\
\hline Peritoneal carcinomatosis and loop colostomy due to frozen pelvis & $2(3.57 \%)$ \\
\hline \multicolumn{2}{|l|}{ TNM Staging } \\
\hline 1 & $9(16.07 \%)$ \\
\hline 2 & $21(37.5 \%)$ \\
\hline 3 & $19(33.92 \%)$ \\
\hline 4 & $7(12.5 \%)$ \\
\hline \multicolumn{2}{|l|}{ Histological findings } \\
\hline Well-differentiated & $6(10.72 \%)$ \\
\hline Moderately differentiated & $36(64.28 \%)$ \\
\hline Poorly differentiated & $14(25 \%)$ \\
\hline Mucinous component & $15(26.7 \%)$ \\
\hline \multicolumn{2}{|l|}{ Morbidity } \\
\hline Superficial wound infection & $4(7.14 \%)$ \\
\hline Anastomosis leakage & $4(7.14 \%)$ \\
\hline Ostomy necrosis & $1(1.78 \%)$ \\
\hline Length of hospital stay (day) & $7.36(5-22)$ \\
\hline Local recurrence & $2(3.57 \%)$ \\
\hline Mortality & $(1.78 \%)$ \\
\hline
\end{tabular}

Tab. 4. Comparison of Prognostic factors.

\begin{tabular}{lccc}
\hline Prognostic Factors & $<50$ age $(\mathrm{n}=56)$ & $>50$ age $(\mathrm{n}=211)$ & $\mathrm{p}$ \\
\hline Low differentiation & $14(25 \%)$ & $26(12.32 \%)$ & ${ }^{a} 0.018^{*}$ \\
Mucinous component & $15(26.7 \%)$ & $22(10.42 \%)$ & ${ }^{a} 0.002^{* *}$ \\
Serosa invasion (T4) & $15(26.7 \%)$ & $30(14.21 \%)$ & ${ }^{a} 0.026^{*}$ \\
Mean lymph node count & 2.071 & 1.53 & ${ }^{b} 0.329$ \\
Number of patients with lymph involvement & $24(42.8 \%)$ & $68(32.2 \%)$ & ${ }^{a} 0.137$ \\
N2 lymph node involvement & $14 \% 25 \%)$ & $29(13.74 \%)$ & ${ }^{a} 0.042^{*}$ \\
Stallite deposit & $3(5.35 \%)$ & $10(4.73 \%)$ & ${ }^{a} 0.849$ \\
Distant metastasis & $7(12.5 \%)$ & $14(6.6 \%)$ & ${ }^{a} 0.147$ \\
TNM Stage 3-4 & $26(46.42 \%)$ & $70(33.17 \%)$ & ${ }^{a} 0.066$ \\
Local recurrence & $2(3.5 \%)$ & $5(2.36 \%)$ & ${ }^{a} 0.729$ \\
\hline
\end{tabular}

${ }^{\mathrm{a}}$ Pearson Chi-Square, ${ }^{\mathrm{b}}$ Independent Sample t test, $* \mathrm{p}<0.05, * * \mathrm{p}<0.001$

ter symptoms started, 24 patients between $1-3$ months, 16 patients between 3-6 months, 6 patients between 6-12 months, and 4 patients 1 year later. In comparison with patients with colorectal cancer over 50 years of age, there was no statistical difference between the mean application times of both groups $(p=0.874)($ Tab. 1).

Tumors were in the right colon in $11(19.64 \%)$ patients, in the transverse colon in $2(3.57 \%)$ patients, in the left colon in $3(46 \%)$ patients, in the sigmoid colon in $9(16.07 \%)$ patients, $7(12.5 \%)$ ) in the upper rectum in patients, in the middle rectum in 4 (7.14 $\%$ ) patients and the lower rectum in $20(35.71 \%)$ patients. In the comparison made with patients over the age of 50 with respect to locations of the tumor, the lower rectal tumors were statistically higher in patients under the age of $50(\mathrm{p}=0.006)$. Sigmoid colon cancers, however, were significantly more common in patients over 50 years of age $(\mathrm{p}=0.039)$ (Tab. 2).

Operations performed on patients under 50 age are detailed in Table 3 . No operationrelated mortality developed in any patient. Anastomosis leakage occurred in 4 patients, while 2 of these patients were treated with an EndoVac therapy system and 2 patients were treated with a colostomy. Superficial wound infection was performed in 4 patients and ostomy revision in 1 patient. The average length of hospital stay of the patients was 7.36 (5-22) days (Tab. 3).

According to TNM staging, $9(16.07 \%)$ patients were stage $1,21(37.5 \%)$ patients were stage 2, 19 (33.92\%) patients were stage 3 and $7(12.5 \%)$ patients were stage 4 . In histological classification, it was seen that $6(10.71 \%)$ patients had well-differentiated, $36(64.28 \%)$ patients had moderately differentiated and 14 (25\%) patients had poorly differentiated tumors. Tumors in 15 patients involved the mucin component (Tab. 3).

The follow-up period of the patients was between 3-36 months, and the mean follow-up was 15.7 months. One of the patients with stage 4 peritoneal carcinomatosis died in the 8th month depending on the course of the disease. In 2 patients, local recurrence occurred in the 14th and 22nd months, respectively, and reoperation was performed.

In patients under the age of 50, higher invasion of the tumor to the serosa, low differentiation of the tumor in terms of histological findings in a higher number of patients, and higher mucinous component of the tumors and higher N2 lymph node involvement ratio were statistically significant when compared to patients over the age of $50(\mathrm{p}=0.026, \mathrm{p}=0.018, \mathrm{p}=0.002, \mathrm{p}=0.042$; respectively $)$. There was no significant difference between these two age groups in terms of mean lymph node number, the number of patients with lymph node involvement, presence of satellite deposit, distant metastasis, local recurrence during the disease stages, and followup periods (Tab. 4).

\section{Discussion}

Colorectal cancer (CRC) is one of the main causes of death with high incidence particularly in developed but also in many 
other countries. However, there has been an increase in the incidence of the disease in developing countries in recent years (14). Although the incidence increases with age, an increase in incidence has also been reported recently in young individuals. Between 2005 and 2014, the incidence of colon cancer increased by $1.4 \%$ and the incidence of rectal cancer increased by $2.4 \%$ annually in individuals under the age of 50 (15).

While the incidence of colorectal cancer under the age of 50 was $6 \%$ in the $1990 \mathrm{~s}$, this rate has increased by up to $10 \%$ in recent years $(6,10-14)$. The incidence of colorectal cancer under the age of 45 was reported to be $5.7 \%$ (15). In a study by Schellerer et al (16), the incidence of cancer under the age of 50 was $12.4 \%$, the incidence of colorectal cancer between the ages of 41-50 was $9.1 \%$, and the incidence of colorectal cancer was $3.2 \%$ in people younger than 40 years. In a recent study by Silva et al (17), cancer incidence was $13.45 \%$ under the age of 50, $5.13 \%$ under the age of 40 , and $8.31 \%$ between the ages of 40 and 50 . The age range of $40-49$ is the period when colorectal cancer is most common under the age of 50 with an incidence rate of $75 \%$ $(18,19)$. In the present study, the incidence of colorectal cancer was $21.05 \%(56 / 266)$ under 50, $12.78 \%(34 / 266)$ under 45 , and $6.76 \%(18 / 266)$ under 40 , and these values were high compared to those in the literature. In the patient series of the present study, the age group of 40-49 was found to be the most common age range for colorectal cancer under the age of 50, with a colorectal cancer rate of $68 \%(38 / 56)$, and was consistent with the results obtained in studies in the literature.

Generally, there are studies reporting that there is no difference in terms of gender distribution in young colorectal cancer patients (19-23). In the patient series in this study, the disease was observed at a higher rate in males than in females $(60.7 \%, 39.28 \%)$.

Numerous types of cancer are associated with body weight. It has been demonstrated that obesity and an obesogenic diet accelerate the multi-stage transition from normal tissue to invasive malignancy and metastatic disease (24). The increase in colorectal cancer in high-income countries may be caused by an obesity epidemic (25). In the study by Kim et al (26), obesity has been observed to be a risk factor for the development of colorectal cancer in patients under the age of 40 . In the present patient series, the BMI average of young patients with colorectal cancer was found to be 27.3, and the patients were found to be overweight.

In the literature, the most common symptoms in patients with colorectal cancer under the age of 50 are rectal bleeding and abdominal pain $(19-22,23)$. In the study by De Sousa et al (27), rectal bleeding was the most common symptom in patients under 50 years of age with an incidence rate of $77 \%$, although there was no difference in symptoms between patients under 50 and over 50 years of age. The change in bowel habits was the most common symptom in patients over 50 years old with a rate of $72 \%$ (27). Rectal bleeding was the most common symptom in patients under 50 years of age, with a rate of $57.2 \%$ in the present study, and it was found statistically significant to be seen at a higher rate than in patients over 50 years of age $(p=0.029)$. Changes in bowel habits in patients over 50 years of age were found statistically higher than those under 50 years of age $(\mathrm{p}=0.032)$. The comparison made in terms of symptom onset time in the study by De Sousa et al (27), the symptom onset times were significantly higher in patients over the age of 50. In this study, the application time under the age of 50 was 4.9 months on average and 4.7 months above the age of 50 , and there was no significant difference between the two groups.

The incidence of colorectal cancer for individuals under the age of 50 increased by $22 \%$ from 2000 to 2013 . These are mostly due to the increase in distal colon and rectum tumors (14). In the study of Silva et al (17), it was seen that the tumor was in the sigmoid colon and rectum in $65 \%$ of patients under 50 years of age. In another study, it was found that the location of the tumor in the distal colon was found to be statistically significant in patients with colorectal cancer under the age of 50 compared to patients over the age of 50 (20). In the study by Wang et al (21), it was significant that tumors were rather located in the rectum in patients under 50 years compared to patients over 50 years of age. In this study, tumors were in the rectum in $55 \%$ of patients under 50 years of age. In comparison with the patients over 50 years of age, it was statistically significant that the tumors were found more in the lower rectum $(p=0.006)$. In patients over 50 years of age, it was significant that tumors were seen more frequently in the sigmoid colon $(p=0.039)$.

Considering the histology of the resected samples, it was seen that the prevalence of tumors with mucin component or poorly differentiated tumors was higher in young patients with colorectal cancer $(23,28)$. In the study by Wang et al $(21)$, poorly differentiated tumor histological types and mucinous components were poor prognostic factors. In the study by Chou et al (29), mucinous component and low differentiation were significantly higher in young patients with colorectal cancer when compared to those in the elderly. In the present patient series, it was statistically significant that the tumors contained mucin components and were low differentiated in patients under 50 years compared to patients over 50 years of age.

Serosal involvement in colorectal cancers is one of the poor prognostic factors associated with decreased survival and may affect additional treatment decisions (30). In a study, the serosal involvement of the tumor was found to be a bad prognostic factor in both univariate analysis and multivariate analysis (21). In a study by Karsten et al (31), it was reported that tumors are at the advanced stage in young colorectal cancer patients and have a high rate of T3 and T4 tumors as $87 \%$ and the tumors in young patients are more aggressive. In the study by Rodriguez et al (9), in a comparison between patients with colorectal cancer under and over 50 years of age, serosal involvement was observed more frequently in patients under the age of 50. In this study, $26.7 \%(15 / 56)$ of patients under the age of 50 were found to have serosal involvement, and serosal involvement was found to be significant in a higher number of patients compared to patients over 50 years of age.

While 5-year survival is $70-80 \%$ in lymph node-negative patients, this rate is between $30-60 \%$ in lymph node-positive patients (32). There are studies with similar lymph node involvement rates in patients aged 50 years and older $(27,33)$. Also, there are studies reporting that the number of lymph node-positive patients is higher in young patients and $\mathrm{N} 2$ as the lymph node involvement stage is higher in young patients $(9,34)$. In the present study, there was no 
432-437

difference between the number of lymph node-positive patients and the average number of lymph nodes with carcinoma metastasis, whereas higher N2 lymph node stages in patients under 50 years of age were found significant.

Many studies have shown that satellite tumor deposits (TDs) are associated with advanced colorectal carcinoma stage and poor prognosis. However, due to the different definitions of TDs, the result data could not be accurately estimated (35). Gopal et al (36) associated TDs with more lymph node involvement, distant metastasis, and decreased survival rates. In this study, satellite tumor deposits in patients under and over 50 years of age were observed at similar rates in both groups.

According to the TNM staging system, the comparison between young and old patients did not differ between tumor stages in most studies $(20,27,33,34,37,38)$. In some studies, stages 3 and 4 diseases were observed at a higher rate in young colorectal cancer patients $(9,21,39)$. In this study, the grade 3-4 disease rate was $46.4 \%$ in young colorectal cancer patients and $33.17 \%$ in patients over 50 years of age. Although this rate was higher in young patients, it was not statistically significant. There was also no difference between the two groups in terms of distant metastases.

Since the implementation of routine screening for colorectal cancer in the 1990s, there have been significant and persistent general decreases in CRC cases and mortality rates $(13,14,24)$. Screening methods such as guaiac test, immunochemical test, DNA tests, and endoscopy are available for colorectal cancer (41). CRC scanning and colonoscopy removal of precancerous lesions is the gold standard (42). In many countries, colonoscopy screening begins between the ages of 50 or 55 . In countries developed in terms of the sociocultural economy such as Germany and England, the colonoscopy screening age is $50(43,44)$. Early-onset colorectal cancers are an undeniable health priority that needs to be addressed internationally, as the risk of colon cancer is doubled, and the risk of rectal cancer is quadrupled in those born in the 1990s (45). The recently published American Cancer Association guidelines suggested starting colonoscopy screening for colorectal cancer at the age of 45 in average-risk populations (13). Early diagnosis is one of the factors that increase survival in colorectal cancer. Perhaps the fact that patients under the age of 50 are not included in screening programs in many countries causes the precancerous lesions of these patients to not be detected and to be diagnosed with cancer at a later stage.

\section{Conclusion}

The fact that the incidence of sporadic colorectal cancer has increased in young ages in recent years has been revealed in our study. In the present study, the incidence of sporadic colorectal cancer under the age of 50 was found to be around $21 \%$. Compared to patients over 50 years of age, it was determined that more patients entered the stage of serosa invasion and N2 lymph involvement, and the tumor histology showed a more aggressive course with low differentiation and more mucin components. We think that the aggressive course of the tumor in patients under the age of 50 is still due to the fact that the population under 50 is still not included in screening programs in many countries around the world. In the present study, $68 \%$ of young patients with colorectal cancer were found to be $40-50$ age range. With these findings, it is considered that screening programs should be reviewed, and the population aged 40 years and older should be included in screening programs and we think that rectoscopy should be performed in the presence of alarm symptoms in patients under the age of 40 because the tumor localization was detected in the left colon and distal in about $80 \%$ of these ages in present study.

\section{References}

1. Ferlay J, Shin HR, Bray F, Forman D, Mathers C, Parkin DM. GLOBOCAN 2008 - cancer incidence and mortality worldwide: IARC CancerBase No 10. Lyon: International Agency for Research on Cancer, 2010. http: //globocan.iarc.fr (accessed April 19, 2013).

2. Siegel R, DeSantis C, Virgo K, Stein K, Mariotto A, Smith T et al. Cancer treatment and survivorship statistics, 2012. CA Cancer J Clin 2012; 62: 220-241.

3. Schreuders EH, Ruco A, Rabeneck L, Schoen RE, Sung JJ, Young GP et al. Colorectal cancer screening: a global overview of existing programmes. Gut 2015; 64: 1637-1649.

4. Bibbins-Domingo K, Grossman DC, Curry SJ, Davidson KW, Epling JW Jr, García FAR et al. Screening for colorectal cancer: US Preventive Services Task Force recommendation statement. JAMA 2016; 315 : 2564-2575.

5. Rex DK, Boland CR, Dominitz JA, Giardiello FM, Johnson DA, Kaltenbach $\mathbf{T}$ et al. Colorectal cancer screening: recommendations for physicians and patients from the U.S. Multi-Society Task Force on Colorectal Cancer. Gastroenterology 2017; 153: 307-323.

6. Surveillance Epidemiology and End Results (SEER) Program. SEER*Stat Database: Mortality-All COD, Aggregated With State, Total US $(1969-2014)<$ Katrina/Rita Population Adjustment> (underlying mortality data provided by the National Vital Statistics System, 2016). Bethesda, MD: National Cancer Institute, Division of Cancer Control and Population Sciences, Surveillance Research Program, Cancer Statistics Branch; 2017.

7. Connell LC, Mota JM, Braghiroli MI, Hoff PM. The rising incidence of younger patients with colorectal cancer: questions about screening, biology, and treatment, Curr Treat Options Oncol 2017; 18 (4): 23.

8. Enblad G, Enblad P, Adami HO, Glimelius B, Krusemo U, Pahlman L. Relationship between age and survival in cancer of the colon and rectum with special reference to patients less than 40 years of age. Br J Surg 1990; 77 (6): 611-616.

9. Rodriguez L, Brennan K, Karim S, Nanji S, Patel SV, Booth CM. Disease characteristics, clinical management, and outcomes of young patients with colon cancer: a population-based study, Clin Colorectal Cancer 2018; 17 (4): e651-e661.

10. Wolf AMD, Fontham ETH, Church TR, Flowers CR, Guerra CE, LaMonte SJ et al. Colorectal cancer screening for average-risk adults: 2018 guideline update from the American Cancer Society. CA Cancer J Clin 2018; 68: 250-281.

11. Surveillance, Epidemiology, and End Results (SEER) Program (www.seer.cancer.gov) SEER*Stat Database: Incidence - SEER 18 Regs Research Data with Delay-Adjustment, Malignant Only, Nov 2015 Sub (2000-2013) - Linked To County Attributes - Total U.S., 1969-2014 Counties, National Cancer Institute, DCCPS, Surveillance Research Program, Surveillance Systems Branch, 2016. 
12. Ferlay I, Soerjomataram I, Dikshit R, Eser S, Mathers C, Rebelo $\mathbf{M}$ et al. Cancer incidence and mortality worldwide: sources, methods and major patterns in GLOBOCAN 2012. Int J Cancer 2015; 136: E359-386.

13. Cancer facts \& figures 2018. Atlanta, Georgia: American Cancer Society 2018. https: //www.cancer.org/content/ dam/cancer-org/research/ cancer-facts-andstatistics/ annual-cancer-facts-and-figures/2018/cancerfactsand- figures-2018.pdf.

14. Siegel RL, Miller KD, Fedewa SA, Ahnen DJ, Meester RGS, Barzi A et al. Colorectal cancer statistics, 2017. CA Cancer J Clin 2017; 67 (3): 177-193.

15. National Cancer Institute Surveillance, Epidemiology, and End Results Program. Cancer stat facts: colon and rectum cancer. http: //seer. cancer.gov/statfacts/html/colorect.html. Accessed April 17, 2017.

16. Schellerer VS, Merkel S, Schumann SC, Schlabrakowski A, Förtsch T, Schildberg C et al. Despite aggressive histopathology survival is not impaired in young patients with colorectal cancer, Int J Colorectal Dis 2012; 27: 71-79.

17. Silva ACB, Vicentini MFB, Mendoza EZ, Fujiki FK, da Fonseca LG, Braghiroli MIFM et al. Young-age onset colorectal cancer in Brazil: Analysis of incidence, clinical features, and outcomes in a tertiary cancer center. Curr Problems Cancer 2019; 43: 377-386.

18. Murphy CC, Lund JI, Sandler RS. Young-Onset Colorectal Cancer: earlier diagnoses or increasing disease burden? Gastroenterology 2017; 152 (8): 1809-1812.

19. Cozart DT, Lang NP, Hauer-Jensen M. Colorectal cancer in patients under 30 years of age. Am J Surg 1993; 166: 764-767.

20. Strum WB, Boland CR. Characterization and Identification of Colorectal Cancer in Persons younger than 50 Years. Clin Gastroenterol Hepatol 2019; 17: 2600-2602.

21. Wang R, Wang MJ, Ping J. Clinicopathological Features and Survival Outcomes of Colorectal Cancer in Young Versus Elderly. Medicine 2015; 94 (35): e1402.

22. Yilmazlar T, Zorluoglu A, Ozguc H, Korun N, Duman H, Kaya E et al. Colorectal cancer in young adults. Tumori 1995; 81: 230-233.

23. Lee PY, Fletcher WS, Sullivan ES, Vetto JT. Colorectal cancer in young patients: characteristics and outcome. Am Surg 1994; 60 (8): $607-$ 612.

24. Berger NA. Young adult cancer: influence of the obesity pandemic. Obesity 2018; 26: 641-650.

25. Young JP, Win AK, Rosty C, Flight I, Roder D, Young GP et al. Rising incidence of early-onset colorectal cancer in Australia over two decades: report and review. J Gastroenterol Hepatol 2015; 30: 6-13.

26. Kim NH, Jung YS, Yang HJ, Park SK, Park JH, Park DI, Sohn CI. Prevalence of and Risk Factors for Colorectal Neoplasia in Asymptomatic Young Adults (20-39 Years Old). Clin Gastroenterol Hepatol 2018. DOI: 10.1016/j.cgh.2018.07.011.

27. De Sousa JB, Souza CS, Fernandes MB, de Castro Durães L, de Almeida et al. Do young patients have different clinical presentation of colorectal cancer causing delay in diagnosis? Internat J Colorectal Dis 2014; 29 (4): 519-527.

28. O’Connell JB, Maggard MA, Livingston EH, Yo CK. Colorectal cancer in the young. Am J Surg 2004; 187 (3): 343-348

29. Chou CL, Chang SC, Lin TC, Chen WS, Jiang JK, Wang HS et al. Differences in clinicopathological characteristics of colorectal cancer between younger and elderly patients: an analysis of 322 patients from a single institution. Amer J Surg 2011; 202 (5): 574-582.

30. Frankel WL, Jin M. Serosal surfaces, mucin pools and deposits, Oh my: challenges in staging colorectal carcinoma. Modern Pathol 2015; 28 (S1): S95-S108.

31. Karsten B, Kim J, King J, Kumar RR. Characteristics of colorectal cancer in young patients at an urban county hospital. Am Surg 2008; 74 (10): 973-976.

32. Ong MLH, Schofield JB. Assessment of lymph node involvement in colorectal cancer. World J Gastrointest Surg 2016; 8 (3): 179.

33. Murata A, Akiyoshi T, Ueno M, Fukunaga Y, Nagayama S, Fujimoto $\mathrm{Y}$ et al. Clinicopathological characteristics of young patients with sporadic colorectal cancer. Surgery Today 2016; 46 (10): 1166-1175.

34. Shemesh-Bar L, Kundel Y, Idelevich E, Sulkes J, Sulkes A, Brenner B. Colorectal Cancer in Young Patients in Israel: A Distinct Clinicopathological Entity? World J Surg 2010; 34 (11), 2701-2709.

35. Greene FL. Tumor deposits in colorectal cancer. A moving target, Ann Surg 2012; 255: 214-214.

36. Gopal P, Lu P, Ayers GD, Herline AJ, Washington MK. Tumor deposits in rectal adenocarcinoms after neoadjuvant chemoradiation are associated with poor prognosis. Modern Pathol 2014; 27: 1281e1287.

37. Jin LX, Inoue N, Sato NK, Matsumoto SM, Kanno HS, Hashimoto YK et al. Comparison between surgical outcomes of colorectal cancer in younger and elderly patients. 2011; 17 (12): 1642-1648.

38. Cheong C, Oh SY, Kim YB, Suh KW. Differences in biological behaviors between young and elderly patients with colorectal cancer. PLOS ONE 2019; 14 (6): e0218604.

39. Kim TJ, Kim ER, Hong SN, Chang DK, Kim YH. Long-term Outcome and Prognostic Factors of Sporadic Colorectal Cancer in Young Patients. Medicine 2016; 95 (19): e3641.

40. Murphy CC, Singal AG, Baron JA, Sandler RS. Decrease in incidence of young-onset colorectal cancer before recent increase. Gastroenterology 2018; 155: 1716-1719.

41. Issa IA, Noureddine M. Colorectal cancer screening: An updated review of the available options. World J Gastroenterol 2017; 23: 5086-5096.

42. Bauer A, Riemann JF, Seufferlein T, Reinshagen M, Hollerbach S, Haug $\mathbf{U}$ et al. Invitation to screening colonoscopy in the population at familial risk for colorectal cancer. Dtch Aerzteblatt Online 2018 [cited 2018 Dec 4]. Available from: URL: https: //www.aerzteblatt.de/pdf/115/43/ m715.pdf?ts $=18 \% 2 \mathrm{E} 10 \% 2 \mathrm{E} 2018+10 \% 3 \mathrm{~A} 29 \% 3 \mathrm{~A} 22$.

43. Gemeinsamer Bundesausschuss. Federal Joint Committee]. Beschluss des Gemeinsamen Bundesausschusses über eine Richtlinie für organisierte Krebsfrüherkennungsprogramme und eine Änderung der Krebsfrüherkennungs-Richtlinie. Decision of the Federal Joint Committee on a directive of organized cancer screening programs and an amendment to the cancer screening directive [In German]. Berlin. 2018.

44. UK National Screening Committee. UK NSC recommendation on bowel cancer screening. 2018.

45. Siegel RL, Fedewa SA, Anderson WF, Kimberly D Miller, Jiemin Ma, Philip S Rosenberg et al. Colorectal Cancer Incidence Patterns in the United States, 1974-2013. J Natl Cancer Inst 2017; 109.

Received November 10, 2020. Accepted November 18, 2020. 